\title{
Patterns of risk-taking behaviors among motorcyclists at signalized intersections in Taiwan
}

\author{
WEN CHIEH YANG, ANJA KATHARINA HUEMER \\ Division of Engineering and Traffic Psychology, Technische Universität Braunschweig, Gaußstraße 23, D-38106 \\ Braunschweig, Germany
}

\begin{abstract}
Motorcyclists ${ }^{1}$ are the fastest-moving vulnerable road users, which made them overrepresented in road injuries and fatalities. In Taiwan, motorcyclists account for approximately $60 \%$ of total road fatalities each year, but little is known about the prevalence of risktaking behaviors among motorcyclists. In the present study, a roadside observation was carried out to examine their unsafe riding behaviors, such as secondary task engagement, helmet non-use, and traffic violations. 4030 motorcyclists were observed at three signalized intersections in Tainan, Taiwan: 593 in a residential district, 1034 in a business park, and 2403 in the city center. $7.3 \%$ of them were engaged in at least one secondary task, with phone use $(3.5 \%)$ being the most common one, followed by chatting with others (1.6\%). Although nearly all riders were helmeted (98.9\%), the majority of the riders used non-standard helmets: $65.2 \%$ wore an open-face helmet, $21.0 \%$ half helmet, and only $12.6 \%$ full-face helmet. $5.9 \%$ of all motorcyclists were observed break-
\end{abstract}

ing at least one traffic rule at the intersections, and the violations that occurred the most often were turn signal neglect $(2.8 \%)$ and red-light running (2.6\%). These risky riding behaviors were also associated with contextual variables and rider characteristics. The likelihood of distracted riding increased at a red light, in the city center, when riders were younger, male, delivery workers, and riding with an adult passenger. Traffic violations were more frequent in the city center, in the afternoon, and on a two-lane road. Furthermore, risk-taking behaviors were more prevalent in un-helmeted riders. Observations in different weather conditions, more traffic contexts, and locations are recommended for future studies to further understand their impact on motorcyclists' adaptive riding behaviors.

KEYWORDS: Motorcyclists; distracted riding; helmet non-use; traffic violations; rider characteristics; contextual risk factors; logistic regression

\section{INTRODUCTION}

Taiwan is a highly urbanized and densely populated nation, making motorcycles an appealing way for daily commutes among many citizens. There are 8 million registered automobiles but over 14 million registered motorcycles, based on the statistics from the Ministry of Transport and Communications in Taiwan (MOTC, 2021). Particularly in cities with less accessible public transportation, motorcycles have been the main mode of transportation since they are usually a more efficient way for commutes than cars or bikes.

Although the number of registered private cars and the availability of public transportation have been increasing in Taiwan, the density of motorcycles per square kilometer in the country remained the highest in the world (MOTC, 2021). Each year, there are more than 13,000 newly registered motorcycles in Taiwan. This number is much higher than other neighboring countries in East Asia: 10,730 in Japan and 2,063 in South Korea. According to a survey by MOTC (2018), 46.6\% of people use motorcycles as their primary mode of transportation, followed by private passenger cars $(26.8 \%)$ and public transportation (13.7\%). On average, motorcyclists spent 51 minutes each day on the road. The same survey also investigated why Taiwanese choose motorcycles for their commute: nearly $80 \%$ of respondents stated that they used motorcycles because of their flexibility. Other notable reasons were shorter commuting time than other means of transportation, inconvenience of public transportation, lower costs, and smaller space required for parking.

1 Motorcycles in this study include mopeds and motor scooters, either powered electrically or by combustion engines that are to be used sitting but do not include the newer "e-scooters" that are used standing up.
Regardless of the benefits that motorcycling may offer, the downside of riding a motorcycle is unignorable. Overrepresentation of motorcyclists in traffic-related deaths is a global phenomenon: only $3 \%$ of registered vehicles are motorcycles in the United States, but motorcyclists made up 14\% of traffic fatalities in 2019 (NHTSA, 2021). The fatality rate for motorcyclists was six times that for private passenger car occupants (58.3 vs. 9.42 per 100,000 registered vehicles). Motorcycles also accounted for $12.0 \%$ of deaths in traffic accidents in South Korea, although only $5 \%$ of all road crashes were motorcycle-related (Chung et al., 2014). In Taiwan, there were 1,837 motorcyclists killed in 2020; the number of deaths was much higher than other road users' (431 pedestrians, 245 cyclists, and 180 passenger car occupants; MOTC, 2021). Traffic injuries among Taiwanese motorcyclists were also shockingly prevalent; there were 374,743 reported motorcycle user injuries in a year, 23 times more than for occupants of passenger cars.

According to the Ministry of Transportation and Communication in Taiwan, motorcyclists accounted for $61 \%$ of total road fatalities (MOTC, 2020). The fatality rate per 100,000 motorcycles was 13.0, which was five times that of private passenger cars (2.6). In most countries, motorcyclists are similarly over-represented in road injuries and deaths. In the US, motorcyclists were 29 times more likely to die in traffic accidents than car drivers per mile traveled (NHTSA, 2021). In Korea, where most motorcycles were used for food or parcel delivery service, motorcycles accounted for $5 \%$ of crashes but $12 \%$ of overall traffic fatalities (Chung et al., 2014). Likewise, $59 \%$ of people that died from a crash in Vietnam were motorcyclists (Nguyen-Phuoc et al., 2019).

Since motorcyclists are one of the most vulnerable road users, there is a need to investigate their risk-taking behav- 
iors to promote road safety. Field observation is a reliable and valid method for researching road users' risky behaviors since self-reports might result in less accurate responses, caused by social desirability and other response biases. Little is known about the prevalence of other risk-taking behaviors among Taiwanese motorcycle users. The present study aims to understand the pervasiveness of unsafe motorcycling behaviors in Taiwan and whether contextual factors and riders' characteristics influence these behaviors.

\section{RELEVANT WORK AND RESEARCH QUESTIONS}

\subsection{Distraction}

Past research has revealed the negative impact of distraction on road safety and driving performance, especially for smartphone screen operation (e.g. Dingus, Klauer, et al., 2006; Victor, Bärgman, et al., 2014; Young, 2017 for naturalistic driving studies or Libby \& Chaparro, 2009; Onate-Vega et al., 2020; Phuksuksakul et al., 2021 Thapa et al., 2015 for experimental studies).

For motorcyclists, riders texting regularly while riding were 2.2 times more likely to be involved in an accident in the past 24 months compared to those who did not text while driving (Truong et al., 2019). In a field study in Taipei, Taiwan, smartphone use while crossing the street was associated with more frequent sudden stops, neglecting traffic signals, and fewer head turn behaviors in pedestrians at urban intersections (Chen et al., 2017). The finding was in line with the crossing behavior among another type of two-wheeler users, cyclists, in the Netherlands: cyclists operating smartphones while riding were less likely to look at their right-hand side than those not distracted (de Waard et al., 2015).

Although most road users are aware of the risk associated with distracted driving, non-driving-related secondary tasks are still widespread. In Germany, for example, 13.2\% of all observed car drivers in a roadside survey were partaking in at least one secondary task (e.g., texting, handsfree phoning, smoking; Vollrath et al., 2016). In another study on distracted driving in Vietnam, 8.4\% of motorcycle and e-bike riders used the phone while riding (Truong et al., 2016). According to a survey, many Vietnamese motorcyclists reported using the phone while riding daily (Truong et al., 2019). The most frequent function was making phone calls (10.2\%), followed by texting (5.3\%) and searching for information (4.3\%). In Taiwan, the ban on handheld phone use started in 2001; the nationwide interview conducted by Woo and Lin (2001) found that $76.8 \%$ of participants believed that phone use while driving was unsafe, but only $44.2 \%$ supported the ban and traffic violation fine. In a study on Taiwanese undergraduates' smartphone dependence, $36 \%$ of participants reported having used their phones while driving a motorcycle or car.

\subsection{Helmet use}

Wearing a helmet is an essential safety precaution for motorcyclists; it can effectively reduce fatal injuries in motorcycle crashes. Pai et al. (2018) analyzed the crash database in Taiwan and found that hospitalization was significantly higher among un-helmeted motorcyclists: the risk of hospitalization increased by $29 \%$ when the motorcyclists in the accident did not wear a helmet. Type of helmet was also associated with the severity of injuries in motorcycle accidents, with full-face helmets being the most effective one for injury prevention. Lam et al. (2020) investigated the inpatients hospitalized for motorcycle accidents from eight hospitals in Taiwan. Seven hundred twenty-five patients filled out a questionnaire on their riding behaviors, details of the accidents, phone use, and helmet type. Overall, $82.9 \%$ of the motorcyclists wore half helmets or open-face helmets while driving, and $17.1 \%$ used full-face helmets. The use of full-face helmets reduced the risk of head injuries from $20.2 \%$ to $12.4 \%$. Those that used phones while riding were 2.2 times more likely to sustain head injuries. The type of helmet used and phone use while riding was also associated with the severity of head injuries. Compared to riders wearing full-face helmets, those using non-standard helmets were 1.3 times more likely to suffer from severe head injuries. Riders using phones were also 2.6 times more likely to sustain severe head trauma.

After the Taiwanese government implemented the mandatory helmet use law in June 1997, the average percentage of helmet use increased from $14.3 \%$ to $73.8 \%$ within half a year according to police accident reports (Chang, 2005). Interestingly, the number of reported motorcycle crashes per month also dropped drastically after the official enforcement of helmet use law on June 1st, 1997. Although the motorcycle fatalities per month remained the same in the year after helmet use became mandatory, the number of injuries per month in motorcycle accidents dropped gradually after June 1997. In Vietnam, where $95 \%$ of registered vehicles were motorcycles, the rate of helmet use remained above 90\% from 2015 to 2019 in an observational study (Li et al., 2020). However, the study revealed a rapid increase in incorrect helmet use (e.g., using non-standard helmets or using unstrapped helmets), which grew from $19.2 \%$ in 2015 to $44.4 \%$ in 2019 . According to another roadside survey in Malaysia, $6.0 \%$ of motorcyclists were traveling without wearing helmets (Rusli et al., 2020). The authors also found that the likelihood of helmet non-use increased when the rider was female and carrying a passenger. Un-helmeted riding was also higher during non-peak hours and on the weekend. Compared to riding on a one-lane road, motorcyclists were less likely to wear a helmet on a multiplelane road. Chi et al. (2019) found for Taiwanese cyclists that unsafe riding behaviors, such as phone use and red-light running, were associated with helmet non-use. Therefore, it is worth examining if un-helmeted motorcyclists are also more prone to other risk-taking behaviors.

\subsection{Traffic violations}

Violating traffic regulations leads to increased crash risk. According to the police report on fatal crashes in 2020, 1702 accidents out of the total 1806 cases in Taiwan were caused by car drivers' or motorcyclists' errors (National Police Agency, 2021). Motorcyclists who report a higher frequency of committing traffic errors have been found to have a higher accident risk (Elliott et al., 2007). Researchers in Taiwan used a self-administered survey to examine motorcyclists' risky riding behaviors and their connection with accident involvement and demographic variables (Chang \& Yeh, 2007). They investigated several violations and errors, such as not using the turn signal, running a red light, violating a two-stage turn, or not keeping a safe distance from heavy vehicles. According to the logistic regression model, violating traffic rules was a significant predictor of motorcycle crashes. The results also revealed a link between younger age and a higher frequency of traffic violations; meanwhile, riders under 20 years old were more likely to report accident involvement than any other age group.

Various studies have investigated the prevalence of different types of traffic violations among motorcycle users. According to a study carried out at 27 intersections in Vietnam, in which 14,750 motorcyclists were observed, the rate of turn-signal neglect was 59.9\% (Nguyen-Phuoc et al., 2019). Another roadside survey in Malaysia found that turn signal neglect was the most prevalent traffic violation among riders: nearly $30 \%$ of motorcyclists did not use turn signals properly (Rusli et al., 2020). In the same Malaysian study, the result showed that the frequency of running a red light among motorcycle riders was $2.8 \%$. The rate of red-light running was higher in female riders and those carrying another 
passenger, while bad weather conditions and on single-lane roads. In general, most studies showed that the frequency of disobeying the traffic signals was higher in younger age groups (Jensupakarn \& Kanitpong, 2018; Porter \& Berry, 2001; Yang \& Najm, 2007).

In Taiwan, it is also compulsory for motorcyclists to perform a two-stage turn instead of making a left turn directly at some of the intersections. Pai et al. (2013) examined the prevalence and influencing factors on the two-stage left turn violation in Taiwan. They found that the violation was more prevalent in rural areas and during off-peak hours. Female and younger motorcyclists were also more likely to violate two-stage turns.

\subsection{Research aims and questions}

The present study aimed to examine the prevalence of different risk-taking behaviors (i.e., distracted riding, helmet nonuse, and traffic violations) among Taiwanese motorcyclists. To understand motorcyclists' adaptive behaviors on the road, it is also crucial to investigate how situational circumstances and rider characteristics influence them. The final aim of the present study was to explore the relationship between distracted riding, helmet non-use, and traffic violations. The research questions were derived accordingly:

RQ1: How prevalent are risk-taking behaviors in Taiwanese motorcyclists?

RQ2: Which secondary tasks are carried out by riders?

RQ3: Are riding behaviors influenced by situational and rider factors?

\section{RQ4: ARE DISTRACTION AND TRAFFIC VIOLATIONS MORE FREQUENT IN HELMET NON-USERS?METHODS}

\subsection{Outcome variables}

The outcome variables measured in this quasi-experimental study were secondary task engagement, helmet use, and traffic violations. Several types of secondary task engagement were considered, including phone use (handheld and on handlebar mount), chatting with others, eating/drinking/ smoking. The one observer (the frist author of this manuscript) also recorded types of helmets that the riders were wearing, namely half helmet, open-face helmet, full-face helmet. Aside from that, she also registered five traffic violations: red-light running, turn signal neglect, riding on a prohibited lane, stopping on zebra crossing while waiting at the traffic light, and not performing a two-stage left turn when it was mandatory at that intersection.

\subsection{Predictors}

Various observational studies have revealed the influences of road users' characteristics and situational circumstances on risk-taking behaviors (e.g., Chen et al., 2017; Huemer et al., 2019; Rusli et al., 2020). Therefore, rider characteristics, location, temporal factors, road design, and weather conditions were considered possible predictors in this study.

\subsubsection{Rider characteristics}

Since the observer could only make a rough estimation of the motorcyclist's age and gender during the roadside observation, she coded each rider into one of the three age groups: young (18 to 30 years old), middle-aged (30 to 50 years old), and older (older than 50 years old). Rider's gender was coded as a binary variable, male and female. Whether the motorcyclist was riding with an adult or child passenger was also observed and recorded. All of the registered motorcycles in Taiwan are required to display a license plate at the rear, with the color of the plate indicating the vehicle's horsepower and whether the vehicle is electric. During the observation, the observer used the license plate to identify the type of motorcycle (electric moped,, ordinary light-duty/heavy-duty scooter, or heavy motorcycle). Whether the rider was working for food delivery was also observed. Delivery riders in Taiwan will carry a food delivery bag on the motorcycle and wear the uniform provided by the delivery service (e.g., Uber Eats and Foodpanda), which makes them distinguishable from other motorcyclists.

\subsubsection{Situational circumstances}

This investigation aimed to understand to what extent motorcyclists adapt their riding behaviors to different traffic contexts. Hence, three locations were selected for examining the effect of locations on riding behaviors: city center, residential district, and business park. Two temporal factors were considered, namely the time of the day and the day of the week. All of the observations took place on weekdays and in the morning (0800-1000), at noon (1200-1400), or in the afternoon (1600-1800). Before each session, the observer would record the traffic volume per minute. Other registered situational variables were weather conditions, the number of traffic lanes, and the traffic signal.

\subsection{Participants}

In total, 4030 motorcyclists at signalized intersections in Tainan were observed within the 72-hour roadside survey, with 2403 in the city center, 593 in the residential district, and 1034 in the business park. The majority of observed motorcyclists were male $(65.5 \% ; n=2638)$, and only one-third of observed motorcyclists were female (34.2\%; $n=1392)$. The observer also classified each rider into three age groups: 2150 were estimated to be young (18 - 30 years old), 1406 were middle-aged ( 30 - 50 years old), and 474 were older than 50 . Table 1 presents the characteristics of the observed motorcyclists.

\subsection{Material}

The software "Observation 3.0" (Ingenieur- und Verkehrspsychologie, TU Braunschweig, 2018) on a tablet was used to collect data efficiently. The observer could register various variables for each observation, such as the location, time of the day, rider's characteristics, and behaviors. Before starting the observation session, she would use the smartphone's timer for counting the traffic flow per minute.

\subsection{Procedure}

The standpoint for the roadside observation was carefully chosen at each corner of the intersection to ensure a precise observation of motorcyclists without getting their attention. In each session, the observer only recorded motorcyclists coming from the same direction. Before starting an observation session, the observer would count the number of passing motor vehicles (i.e., cars and motorcycles) from the same direction for three minutes and register the average traffic flow per minute in the software. Aside from the traffic flow, she would also record other contextual variables (location, direction of motorcyclists coming from, weather conditions, time of the day, and day of the week). She observed the motorcyclists passing the intersection at both green and red lights. To ensure a random sample, the motorcyclist who first reached the stop line during green traffic lights was selected. As to the observation of motorcyclists waiting at the red light, the observer would record the motorcyclists nearest the stop line until the signal light changed.

\subsection{Time and location}

Since one of the research aims was to examine how temporal factors influence riders' behaviors, the roadside survey was carried out in the morning (0800-1000), at noon (1200-1400), and in the afternoon (1600-1800). Observations for each lo- 


\begin{tabular}{|c|c|c|c|}
\hline Variables & Levels & $\mathbf{n}$ & $\%$ \\
\hline \multirow[t]{3}{*}{ Location } & City center & 2403 & $59.6 \%$ \\
\hline & Residential district & 593 & $14.7 \%$ \\
\hline & Business park & 1034 & $25.7 \%$ \\
\hline \multirow[t]{5}{*}{ Day of the week } & Monday & 1006 & $25.0 \%$ \\
\hline & Tuesday & 1085 & $26.9 \%$ \\
\hline & Wednesday & 965 & $23.9 \%$ \\
\hline & Thursday & 953 & $23.6 \%$ \\
\hline & Friday & 21 & $0.5 \%$ \\
\hline \multirow[t]{3}{*}{ Time of the day } & Morning & 1221 & $30.3 \%$ \\
\hline & Noon & 1406 & $34.9 \%$ \\
\hline & Afternoon & 1403 & $34.8 \%$ \\
\hline \multirow[t]{2}{*}{ Traffic flow } & Low density & 1915 & $47.5 \%$ \\
\hline & High density & 2115 & $52.5 \%$ \\
\hline \multirow[t]{3}{*}{ Road design } & 1 Lane & 1967 & $48.8 \%$ \\
\hline & 2 Lanes & 1545 & $38.3 \%$ \\
\hline & 3 Lanes & 518 & $12.9 \%$ \\
\hline \multirow[t]{4}{*}{ Direction } & Straight & 3402 & $84.4 \%$ \\
\hline & Right & 290 & $7.2 \%$ \\
\hline & Left & 284 & $7.0 \%$ \\
\hline & U-turn & 54 & $1.3 \%$ \\
\hline
\end{tabular}

\begin{tabular}{|c|c|c|c|}
\hline Variables & Levels & $\mathbf{n}$ & $\%$ \\
\hline \multirow[t]{2}{*}{ Traffic light } & Green & 2006 & $49.8 \%$ \\
\hline & Red & 2024 & $50.2 \%$ \\
\hline \multirow[t]{3}{*}{ Motorcycle type } & Electric mopeds & 14 & $0.3 \%$ \\
\hline & Scooter & 4001 & $99.3 \%$ \\
\hline & Heavy motorcycle & 15 & $0.4 \%$ \\
\hline \multirow[t]{3}{*}{ Age } & Young & 2150 & $53.3 \%$ \\
\hline & Middle-aged & 1406 & $34.9 \%$ \\
\hline & Older & 474 & $11.8 \%$ \\
\hline \multirow[t]{2}{*}{ Gender } & Female & 1392 & $34.5 \%$ \\
\hline & Male & 2638 & $65.5 \%$ \\
\hline \multirow[t]{2}{*}{ Delivery worker } & No & 3865 & $95.9 \%$ \\
\hline & Yes & 165 & $4.1 \%$ \\
\hline \multirow[t]{5}{*}{ Passenger } & None & 3630 & $90.1 \%$ \\
\hline & 1 child & 70 & $1.7 \%$ \\
\hline & 1 adult & 324 & $8.0 \%$ \\
\hline & Child and adult & 3 & $0.1 \%$ \\
\hline & 2 Children & 3 & $0.1 \%$ \\
\hline
\end{tabular}

Table 1: Sample characteristics

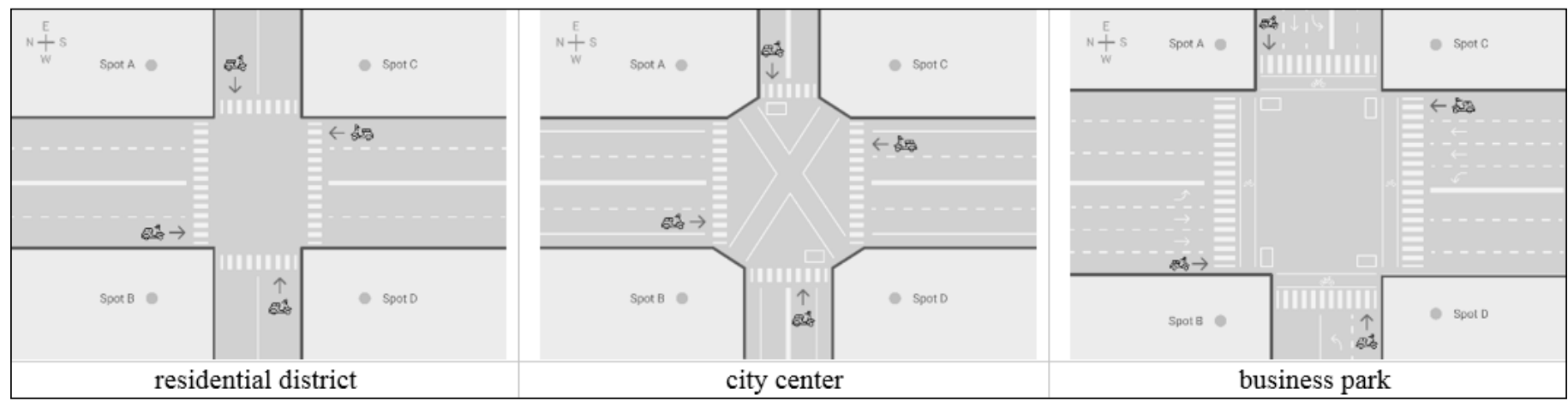

Figure 1: Layout of the intersections

cation were conducted on different days of the week, from Monday to Friday. Each observation session took one hour and consisted of 45 minutes of observation followed by a 15-minute break to ensure the quality of observation. The observation took place during the springtime in Taiwan (March and April 2021). The weather was warm and clear, and the road surface was dry throughout the 72 sessions. Three signalized intersections in a medium-sized city in south Taiwan, Tainan, were selected for the roadside survey. Each of the intersections was representative of the traffic context for the three areas for exploring the contextual influences on motorcyclists' behaviors. The layout of the three signalized intersections is presented in Figure 1. The observation was indirect and hidden to avoid possible behavioral changes among motorcyclists due to the observer's presence. The observer would change the observation point between $\mathrm{A}$ and $\mathrm{D}$ depending on the motorcyclists' traveling direction to ensure that she could see their behaviors clearly without getting spotted.

The first intersection was in the city center of Tainan, where the traffic was heavy throughout the day. At this $1 \times 2$ intersection, no separate motorcycle lanes were available; all of the motorcyclists at this location rode on joint lanes with other motor vehicles. The speed limits for the two directions were 30 and $50 \mathrm{~km} / \mathrm{h}$. Besides the traffic signal for motor vehicles, there was a signal for diagonal crossing for pedestrians at this intersection. Motorcyclists coming from the north and the south should perform a two-stage left turn using the queue box.

The second observation site was in a business park (i.e., Tainan Science Park), and the area mainly consisted of office buildings and factories. This area was also full of large intersections with multiple lanes, and the traffic was heavy in rush hours (0800-1000 and 1600-1800). There was a separate lane for motorcycles in both directions at this intersection, and the speed limits were 40 and $60 \mathrm{~km} / \mathrm{h}$. The use of a two-stage turn at this $2 \times 3$ junction was obligatory for all motorcyclists when making a left turn.

Lastly, the third location was in a residential area, in which the traffic flow was usually relatively low at all times. There was a motorcycle lane for riders from the north and south, while riders from the east and west drove on a joint lane with other motor vehicles. The speed limits were $50 \mathrm{~km} / \mathrm{h}$ for both ways. It was a 1x2 intersection without any 2-stage turn queue box, at which motorcyclists could make a left turn directly during the green light. To sum up, a total of 72 hours of observation was done at the three different locations: 24 hours per location, with eight hours in the morning, at noon, and in the afternoon, respectively. 


\subsection{Data analysis}

Text files by the Observation 3.0 program were converted into CSV files; statistical analysis was carried out in $\mathrm{R}$ (R Core Team, 2021). First, summary statistics were calculated to understand the prevalence of risk-taking behaviors among observed motorcyclists. Second, logistic regression models were computed to predict three binary outcome variables, namely "engagement in any secondary task," "phone use," and "carrying out any traffic violation". Due to complete separation, logistic regression models for "helmet use" as well as behaviors under the cluster "secondary tasks" and "traffic violations" were not calculated. The forced entry method was chosen for the model selection to investigate the effect of every possible predictor. The weather condition and day of the week were excluded from the model because all observations were on weekdays, and the weather was clear in all sessions. Motorcycle type was not included as a predictor as too few observations were made for electric mopeds and heavy motorcycles. The models did not incorporate interaction terms due to the relatively large number of predictors.

A median split was carried out to separate traffic density into "low" and "high" for each observation location separately due to the variation of traffic flow between these three places. The median traffic density among the 24 sessions at the city center was 18.5 (vehicles per minute), 2.5 in the residential district, and 9 in the business park. In other words, the categorical predictor "traffic density" differentiated the traffic context within a location. Finally, a cross-tabulation for the frequency of helmet use and secondary task engagement, and another one for helmet use and traffic violation were created to examine the association between these three risky riding behaviors. Two Pearson's Chi-squared tests were calculated to better understand their associations.

\section{RESULTS}

\subsection{Secondary task engagement}

Two hundred ninety-four motorcyclists were engaged in at least one secondary activity while riding, which is $7.3 \%(95 \%$ CI: $6.5 \%-8.1 \%$ ) of all observed 4030 riders. A small proportion of motorcyclists was found partaking in two secondary tasks simultaneously (0.2\%; 95\%CI: $0.1 \%$ - 0.4\%). Figure 2 gives an overview of secondary task engagement. The most prevalent secondary task was phone use: in total, there were 140 (3.5\%; 95\% CI: 2.9\% - 4.0\%) motorcyclists holding and operating the phone, while 48 (1.2\%; $95 \%$ CI: $0.9 \%-1.5 \%)$ motorcyclists were operating the phone on the handlebar mount. 63 (1.6\%; 95\% CI: 1.2\% - 1.9\%) motorcyclists were chatting, either with the passenger they were carrying or with another rider. During the observation, 42 (1.0\%; 95\% CI: $0.7 \%-1.4 \%$ ) individuals were found eating, drinking and smoking, and 10 (0.2\%; 95\% CI: 0.1\% - 0.4\%) were carrying out other activities.

The predictors for any secondary task in the logistic regression model were location, time of the day, traffic density, number of lanes, traffic signal, gender, age, riding as a delivery worker, and passenger presence. The model was significant $\left(\chi^{2}(14)=286.168, p<.001\right)$ and could explain $16.9 \%$ of the variance (Nagelkerke $\mathrm{R}^{2}$ ). Table 2 shows the model results and the odds ratio for individual predictors with a $95 \%$ confidence interval. Significant predictors for any secondary task activity included location, traffic signal, age, gender, delivery worker, and riding with an adult passenger. Figure 4 is the odds ratio plot exhibiting the ORs of all significant predictors, and the ORs were converted to be greater than 1 for a more explicit comparison of their distribution. With an OR of 8.19 compared to green lights, riders at red lights were more likely to be engaged in a secondary task. The OR of delivery workers was 3.39, indicating a higher rate of distracted riding in them than non-delivery riders. Riding with an adult passenger also increased the odds of distraction, with an OR of 2.17 compared to riding alone. The location of the intersection also influenced the likelihood of distracted riding. Motorcyclists in the city center had an OR of 1.95, indicating more engagement in any secondary task in this area than in the residential district. Age was another influencing factor for the prediction of distraction. Young riders had an OR of 2.00 and 1.40 compared to older and middle-aged riders respectively, meaning more distraction in the youngest age group. The prevalence of distraction was also higher in male riders, with an OR of 1.37 compared to female riders.

Another logistic regression model was computed to predict phone use while riding. Phone handheld and phone on the handlebar mount were combined into one outcome variable since the frequency counts were low in both categories. Table 3 shows the model results, while the ORs of the significant predictors are visualized in Figure 5. The model for phone use was significant and explained $20.1 \%$ of the variance $\left(\chi^{2}(14)=262.719, \mathrm{p}<.001\right.$, Nagelkerke $\mathrm{R}^{2}=$ $0.201)$. The strongest predictors for phone use were waiting at a red light $(\mathrm{OR}=11.47)$, being a delivery worker $(\mathrm{OR}=$ $5.46)$, and riding alone $(\mathrm{OR}=5.06)$. Phone use was also more frequent in young riders than middle-aged $(\mathrm{OR}=1.75)$ and older riders $(\mathrm{OR}=4.81)$. Contextual factors that influenced the odds of phone use were location and the number of lanes. Motorcyclists in the city center were more likely to use the phone than in the residential district $(\mathrm{OR}=2.31$ ); however, those riding in the business park were even more prone to phone use than in the city center with an OR of 1.79. The frequency of phone use also increased when the motorcyclists were riding on a single-lane road compared to a two-lane road $(\mathrm{OR}=1.74)$.
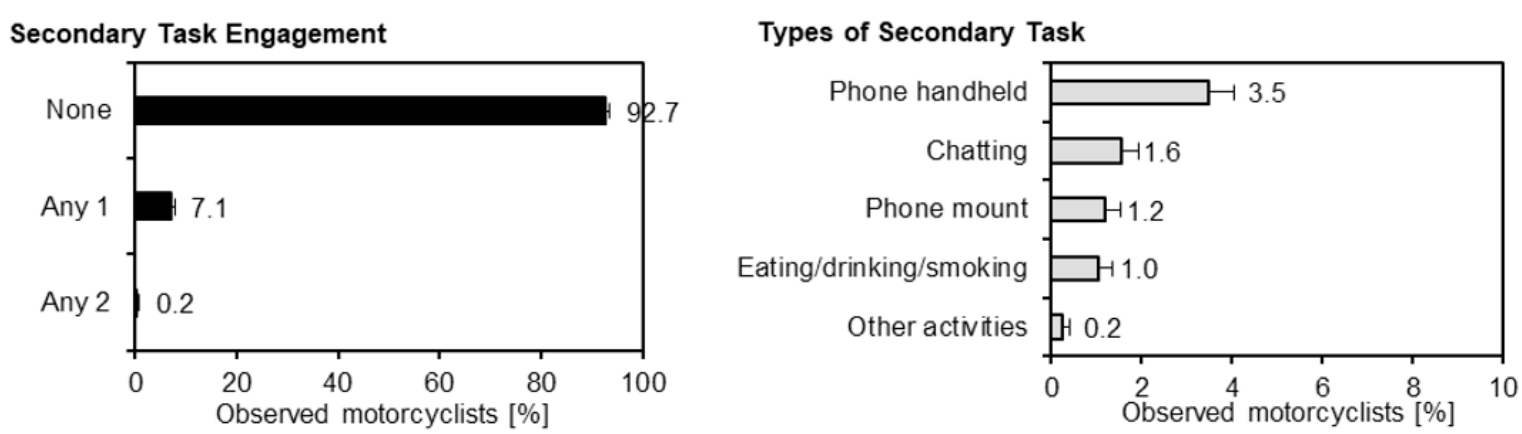

Figure 2: Percentages of number (left) and types (right) of secondary task engagement among observed motorcyclists. Error bars show 95\% CI 


\begin{tabular}{|c|c|c|c|c|c|c|}
\hline \multirow[b]{2}{*}{ Predictor } & \multirow[b]{2}{*}{ B } & \multirow[b]{2}{*}{ Wald } & \multirow[b]{2}{*}{$\mathbf{p}$} & \multirow[b]{2}{*}{ OR } & \multicolumn{2}{|c|}{ 95\% CI } \\
\hline & & & & & Lower & Upper \\
\hline Business park (ref.: City center) & 0.35 & 1.73 & 0.083 & 1.42 & 0.95 & 2.12 \\
\hline Residential district (ref.: City center) & -0.67 & -2.56 & 0.011 & 0.51 & 0.30 & 0.84 \\
\hline Afternoon (ref.: Noon) & 0.29 & 1.91 & 0.056 & 1.34 & 0.99 & 1.82 \\
\hline Morning (ref.: Noon) & -0.14 & -0.82 & 0.412 & 0.87 & 0.62 & 1.22 \\
\hline Low density (ref.: High density) & -0.06 & -0.38 & 0.703 & 0.94 & 0.70 & 1.28 \\
\hline 2 lanes (ref.: 1 lane) & -0.29 & -1.45 & 0.147 & 0.75 & 0.51 & 1.10 \\
\hline 3 lanes (ref.: 1 lane) & -0.12 & -0.40 & 0.687 & 0.89 & 0.50 & 1.56 \\
\hline Red light (ref.: Green light) & 2.10 & 11.31 & 0.000 & 8.19 & 5.77 & 11.98 \\
\hline Female (ref.: Male) & -0.31 & -2.12 & 0.034 & 0.73 & 0.55 & 0.97 \\
\hline Middle-aged (ref.: Young) & -0.34 & -2.40 & 0.016 & 0.71 & 0.54 & 0.94 \\
\hline Older (ref.: Young) & -0.69 & -2.85 & 0.004 & 0.50 & 0.30 & 0.79 \\
\hline Delivery worker (ref.: Non-delivery) & 1.22 & 5.28 & 0.000 & 3.39 & 2.13 & 5.28 \\
\hline With adult passenger (ref.: Alone) & 0.77 & 3.96 & 0.000 & 2.17 & 1.46 & 3.15 \\
\hline With child passenger (ref.: Alone) & -0.23 & -0.31 & 0.757 & 0.79 & 0.13 & 2.72 \\
\hline
\end{tabular}

Table 1: Results of the logistic regression model for any secondary task

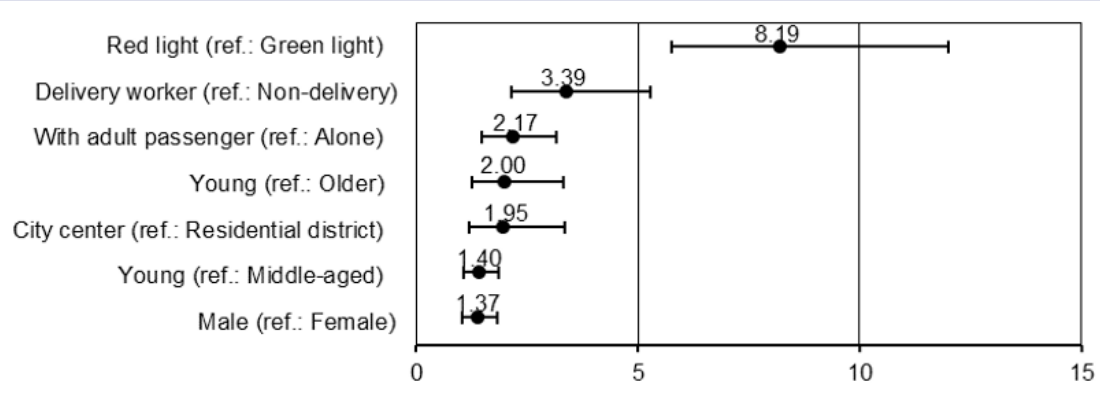

Figure 3: Odds ratios of significant predictors for any secondary task and the $95 \% \mathrm{CI}$

\begin{tabular}{|c|c|c|c|c|c|c|}
\hline \multirow[b]{2}{*}{ Predictor } & \multirow[b]{2}{*}{ B } & \multirow[b]{2}{*}{ Wald } & \multirow[b]{2}{*}{$\mathbf{p}$} & \multirow[b]{2}{*}{ OR } & \multicolumn{2}{|c|}{ 95\% CI } \\
\hline & & & & & Lower & Upper \\
\hline Business park (ref.: City center) & 0.58 & 2.30 & 0.021 & 1.79 & 1.09 & 2.94 \\
\hline Residential district (ref.: City center) & -0.84 & -2.46 & 0.014 & 0.43 & 0.21 & 0.81 \\
\hline Afternoon (ref.: Noon) & 0.23 & 1.19 & 0.235 & 1.26 & 0.86 & 1.86 \\
\hline Morning (ref.: Noon) & 0.04 & 0.21 & 0.831 & 1.04 & 0.70 & 1.56 \\
\hline Low density (ref.: High density) & 0.20 & 1.05 & 0.295 & 1.22 & 0.84 & 1.77 \\
\hline 2 lanes (ref.: 1 lane) & -0.56 & -2.20 & 0.028 & 0.57 & 0.35 & 0.94 \\
\hline 3 lanes (ref.: 1 lane) & -0.14 & -0.39 & 0.696 & 0.87 & 0.44 & 1.72 \\
\hline Red light (ref.: Green light) & 2.44 & 9.13 & 0.000 & 11.47 & 7.01 & 20.12 \\
\hline Female (ref.: Male) & -0.13 & -0.73 & 0.466 & 0.88 & 0.62 & 1.23 \\
\hline Middle-aged (ref.: Young) & -0.56 & -3.18 & 0.001 & 0.57 & 0.40 & 0.80 \\
\hline Older (ref.: Young) & -1.57 & -3.68 & 0.000 & 0.21 & 0.08 & 0.44 \\
\hline Delivery worker (ref.: Non-delivery) & 1.70 & 6.92 & 0.000 & 5.46 & 3.34 & 8.76 \\
\hline With adult passenger (ref.: Alone) & -1.62 & -2.74 & 0.006 & 0.20 & 0.05 & 0.53 \\
\hline With child passenger (ref.: Alone) & 0.30 & 0.40 & 0.687 & 1.36 & 0.21 & 4.78 \\
\hline
\end{tabular}

Table 2: Results of the logistic regression model for phone use

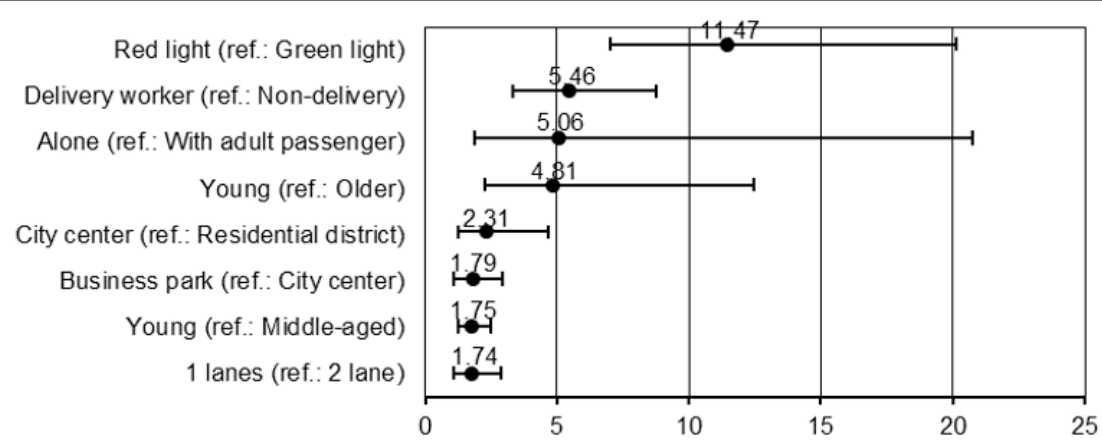

Figure 4: Odds ratios of significant predictors for phone use and the $95 \%$ CI 
Traffic signal condition was the strongest predictor for secondary task engagement for both analyses. Figure 5 shows the percentages of types of secondary task engagement among observed motorcyclists by traffic signal condition. Handheld phone use was observed for 0.6\% (95\% CI: $0.6 \%$ $0.6 \%$ ) riders riding through green traffic lights but for $6.3 \%$ (95\% CI: $6.2 \%-6.4 \%$ ) of riders stopping at red lights. Chatting was observed for $0.5 \%$ (95\% CI: $0.5 \%-0.5 \%$ ) riders riding through green traffic lights but for $2.6 \%$ (95\% CI: $2.5 \%-2.7 \%)$ of riders stopping at red lights. Use of mounted phones was observed for $0.2 \%$ (95\% CI: $0.2 \%-0.2 \%)$ riders riding through green traffic lights but for $2.2 \%$ (95\% CI: $2.1 \%-2.3 \%$ ) of riders stopping at red lights. Eating/drinking/smoking was observed for $0.3 \%$ (95\% CI: $0.3 \%-0.3 \%)$ riders riding through green traffic lights but for 1.8\% (95\% CI: 1.7\% - 1.9\%) of riders stopping at red lights. Finally, any other activity was observed for $0.1 \%$ (95\% CI: $0.1 \%-0.1 \%$ ) riders riding through green traffic lights but for $0.3 \%$ (95\% CI: $0.3 \%-0.3 \%)$ of riders stopping at red lights.

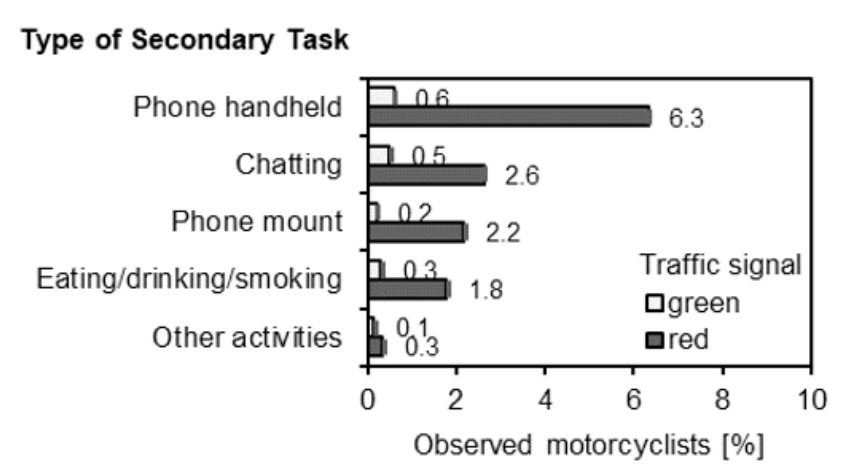

Figure 5: Percentages of types of secondary task engagement among observed motorcyclists by traffic signal condition. Error bars show $95 \%$ CI

\subsection{Helmet use}

Among 4030 observed motorcyclists, only 46 (1.1\%; 95\% CI: $0.8 \%-1.5 \%)$ rode without wearing a helmet. 2629 (65.2\%; $95 \%$ CI: $63.8 \%$ - 66.7\%) used an open-face helmet, which was the most common one. 848 (21.0\%; 95\% CI: 19.8\% - 22.3\%) wore a half helmet while riding the motorcycle, and 507 (12.6\%; 95\% CI: $11.6 \%$ - 13.6\%) wore a full-face helmet. Figure 3 demonstrates the percentage of different helmet types used by motorcyclists. Although almost all observed riders were helmeted (98.9\%), most of them used a non-standard helmet (86.2\%) instead of a standard full-face motorcycle helmet.

\subsection{Traffic violations}

Figure 3 illustrates the percentages of traffic violations by observed motorcyclists. 236 out of the 4030 motorcyclists were found breaking at least one traffic regulation $(5.9 \%$; 95\% CI: $5.1 \%-6.6 \%$ ) in the observation. The traffic violation that occurred most frequently at these three intersections was turn-signal neglect (2.8\%; 95\% CI: $2.2 \%-3.3 \%)$, followed by red-light running (2.6\%; $95 \%$ CI: $2.1 \%-3.1 \%)$. 104 motorcyclists in total ran through a red light, which accounted for $5.1 \%$ of the 2024 observations during red lights. $1.3 \%$ (95\% CI: $0.9 \%-0.6 \%$ ) of motorcyclists rode on a prohibited lane. We also observed a small percentage (0.4\%; $95 \%$ CI: $0.2 \%-0.7 \%$ ) of motorcyclists stopping on the zebra crossing in front of the stop line at the intersection while waiting at a red light. $0.2 \%$ (95\% CI: $0.0 \%-0.3 \%)$ of all observed motorcyclists neglected the two-stage left turn; to be more specific, 628 motorcyclists made a turn at the intersection, and 111 of them were found not using the turn signal (17.6\%).

The logistic regression model results for any traffic violation are presented in Table 4 . The traffic signal was not included as a predictor in the regression model since some of the violations were related to the signal status. The model for any traffic violation was significant and could explain $10.3 \%$ of the variance $\left(\chi^{2}(13)=151.820, p<.001\right.$, Nagelkerke $\left.\mathrm{R}^{2}=0.103\right)$. The ORs of the three significant predictors are plotted in Figure 6, namely location, time of the day, and the number of lanes. Compared to riding in the city center, motorcyclists in the residential district were more likely to violate the traffic law $(\mathrm{OR}=4.60)$. The odds of any traffic violation also increased when motorcyclists rode on a onelane road compared to a two-lane road ( $\mathrm{OR}=1.88)$. Riding at noon had an OR of 1.58 compared to riding in the afternoon, indicating more frequent traffic violations at noon.

\subsection{Risk-taking behaviors among delivery riders}

Figure 7 shows the percentage of phone use and traffic violation among delivery and non-delivery riders. The frequency of mobile phone use was significantly higher in delivery workers than ordinary motorcyclists $(18.2 \%$ vs. 4.1\%). Delivery riders also carried out traffic violations more often: $8.5 \%$ of them (95\% CI: $4.2 \%$ - 12.7\%) were observed violating at least one traffic regulation while $5.7 \%$ (95\% CI: $5.0 \%-6.5 \%$ ) of non-delivery riders were observed doing so.

\subsection{Association between risk-taking behaviors}

Two Pearson's chi-squared tests were conducted to investigate if helmet use was associated with distracted riding and traffic violation. Motorcyclists riding without wearing a helmet were more likely to be distracted $\left(\chi^{2}(1)=4.317\right.$, $\mathrm{p}=0.038$ ), but the effect size was minimal (Cramer's $\mathrm{V}=$ 0.033). $15.2 \%$ of helmet non-users were distracted while riding, while the frequency was only $7.2 \%$ in helmet users. Another chi-squared test was calculated for helmet use and any traffic violation. The distribution of traffic violation
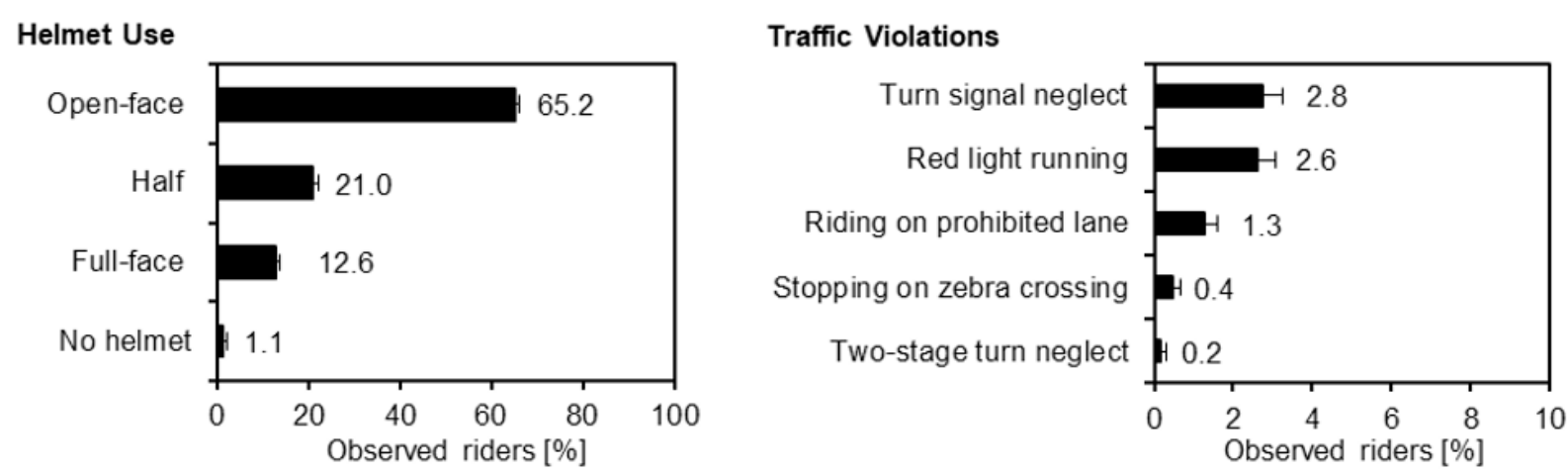

Figure 6: Percentage of helmet use (left) and traffic violations (right) among motorcycle riders. Error bars show $95 \%$ CI 


\begin{tabular}{|c|c|c|c|c|c|c|}
\hline \multirow[b]{2}{*}{ Predictor } & \multirow[b]{2}{*}{ B } & \multirow[b]{2}{*}{ Wald } & \multirow[b]{2}{*}{$\mathbf{p}$} & \multirow[b]{2}{*}{ OR } & \multicolumn{2}{|c|}{ 95\% CI } \\
\hline & & & & & Lower & Upper \\
\hline Business park (ref.: City center) & 0.28 & 0.93 & 0.353 & 1.33 & 0.72 & 2.39 \\
\hline Residential district (ref.: City center) & 1.53 & 8.73 & 0.000 & 4.60 & 3.28 & 6.51 \\
\hline Afternoon (ref.: Noon) & -0.46 & -2.53 & 0.011 & 0.63 & 0.44 & 0.90 \\
\hline Morning (ref.: Noon) & -0.05 & -0.30 & 0.761 & 0.95 & 0.68 & 1.32 \\
\hline Low density (ref.: High density) & 0.21 & 1.29 & 0.196 & 1.23 & 0.90 & 1.70 \\
\hline 2 lanes (ref.: 1 lane) & -0.63 & -2.49 & 0.013 & 0.53 & 0.32 & 0.87 \\
\hline 3 lanes (ref.: 1 lane) & -0.36 & -0.90 & 0.367 & 0.70 & 0.32 & 1.53 \\
\hline Female (ref.: Male) & -0.28 & -1.86 & 0.063 & 0.75 & 0.56 & 1.01 \\
\hline Middle-aged (ref.: Young) & -0.09 & -0.61 & 0.544 & 0.91 & 0.68 & 1.22 \\
\hline Older (ref.: Young) & -0.22 & -0.91 & 0.363 & 0.80 & 0.49 & 1.26 \\
\hline Delivery worker (ref.: Non-delivery) & 0.00 & -0.01 & 0.990 & 1.00 & 0.53 & 1.75 \\
\hline With adult passenger (ref.: Alone) & -0.62 & -1.93 & 0.054 & 0.54 & 0.27 & 0.97 \\
\hline With child passenger (ref:: Alone) & -0.43 & -0.88 & 0.376 & 0.65 & 0.22 & 1.55 \\
\hline
\end{tabular}

Table 3: Results of the logistic regression model for any traffic violation

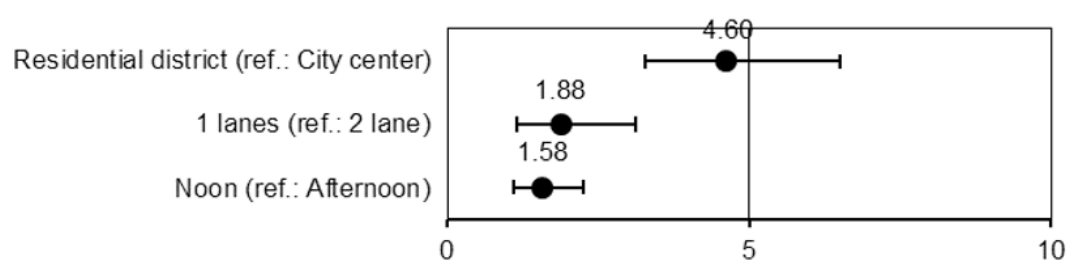

Figure 7: Odds ratios of significant predictors for any traffic violation and the $95 \% \mathrm{CI}$
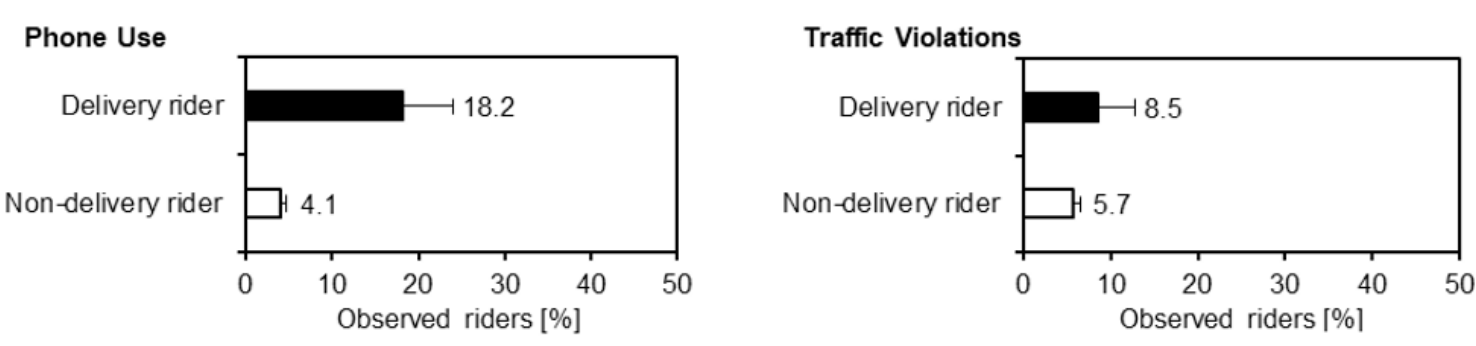

Figure 8: Percentage of delivery riders and non-delivery riders using the phone (left) and carrying out traffic violations (right). Error bars show $95 \%$ CI

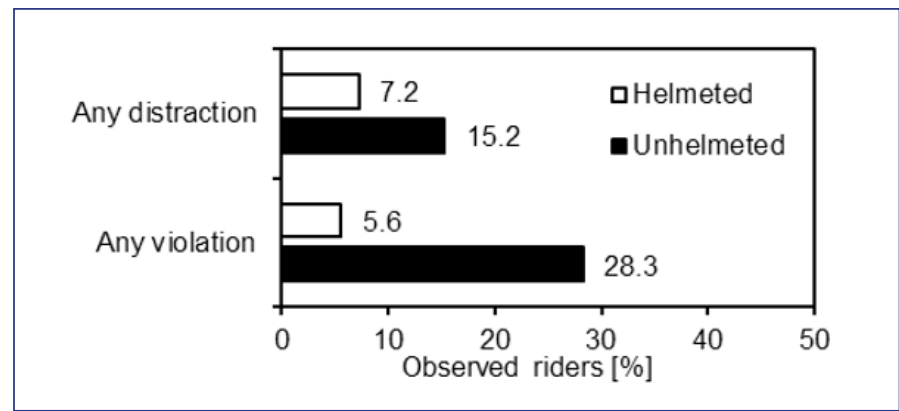

Figure 9: Percentages of distraction and traffic violation in helmeted and un-helmeted riders

between helmet users and non-users was statistically significant $\left(\chi^{2}(1)=42.366, \mathrm{p}<0.001\right)$ with a small effect size (Cramer's V = 0.103). In other words, helmet users were less likely to carry out other traffic violations. The frequency of traffic violations in helmet non-users (28.3\%) was much higher than helmet users (5.6\%). Figure 8 illustrates the different rates of distraction and traffic violation in helmeted and un-helmeted riders.

\section{DISCUSSION}

\subsection{Prevalence of risk-taking behaviors in Taiwanese} motorcyclists

Among the 4030 motorcyclists at the three observation sites, $7.3 \%$ were distracted while riding. The most common secondary task in Taiwanese motorcyclists was phone use; $4.7 \%$ of them used the phone while riding. The second most frequently observed activity was chatting with the passenger or another motorcyclist (1.6\%).

Phone use seemed to be the most common distraction among different road users and was almost always investigated in observational studies on secondary task engagement (Huemer et al., 2018). The prevalence of phone use in this study was overall higher than in Malaysian motorcyclists, where only $0.2 \%$ of motorcyclists used mobile phones while riding (Rusli et al., 2020). The difference, however, might be caused by research methodologies and contextual factors. Although Rusli et al. (2020) did the observations at intersections, it was not clear if they only recorded moving motorcycles. In our study, both moving and stationary motorcycles were recorded. Riders waiting at a red light were much more 
likely to initiate phone operations than those traveling by during a green light (6.3\% vs. $0.6 \%$ ). In another observational study conducted in Mexico, the prevalence of phone use in motorcyclists was the same as for moving vehicles in Taiwan (Pérez-Núñez et al., 2014): $0.6 \%$ vs. $0.6 \%$. Nevertheless, the observation in the Mexican study was carried out between 2011 and 2012, when ownership of smartphones globally was considerably lower than in 2021. For the Mexican study, it is also not clear if only moving vehicles or also those stopping at red lights were included. In West European countries, bikes are a more common way of commuting than motorcycles; the observational survey by Huemer et al. (2019) investigated the phone use rate in German cyclists and found that $2.0 \%$ of riders used the phone while cycling. This rate was higher than the rate of phone use for moving vehicles in the presents study in Taiwan $(0.8 \%)$. Furthermore, the most prominent distraction in German cyclists was using headphones or earphones, which was not easy to observe in motorcyclists due to motorcycle helmets.

The use of helmets can reduce the risk of fatal injuries in motorcycle crashes. Among the motorcycle casualties in Taiwan between 2011 to 2016 , around $10 \%$ of the motorcyclists did not use helmets while riding (Wiratama et al., 2020). The un-helmeted riders or passengers were much more prone to fatal injuries $(\mathrm{OR}=3.1)$ than the helmeted. Based on our roadside observation in Tainan, the percentage of helmet use was relatively high among Taiwanese motorcyclists; 3986 out of the 4030 riders used helmets (98.9\%). The observational study in Malaysia showed that the rate of helmeted riding was $94.0 \%$ (Rusli et al., 2020). In another observational survey in Vietnam, the helmet-wearing rate was between $91.1 \%$ to 96.0\%; however, they found an increasing trend of incorrect helmet use, such as wearing a helmet unstrapped (Li et al., 2020). To sum up, almost all of the observed motorcyclists in Taiwan wore helmets while riding, and the percentage was slightly higher than neighboring Asian nations with high usage of motorcycles.

$5.9 \%$ of observed riders broke at least one traffic regulation, while turn signal neglect (2.8\%) being the most prevalent one in Taiwanese motorcyclists. Among the 628 riders making a turn, 111 were found not using the turn signal (17.6\%). The second most frequently observed traffic violation was red-light running (2.6\%). Among the 2024 riders observed during red lights, 104 neglected the traffic signal (5.1\%). The frequency of red-light running was similar in Malaysia, in which they found $2.8 \%$ of all observed riders running a red light at intersections (Rusli et al., 2020). However, turn signal neglect was much more widespread in Malaysia (29.7\%). In Vietnam, turn signal neglect was also common in both car drivers and motorcycle riders; among those making a turn, $31.7 \%$ and $59.9 \%$ of them did not use turn signals (NguyenPhuoc et al., 2019).

\subsection{Influences of situational} and rider factors on riding behaviors

Factors associated with a higher likelihood of engaging in any secondary task were waiting at a red light, being a delivery worker, riding with an adult passenger, while the risk of distraction decreased with middle-aged and older riders and in the residential district. Phone use while riding increased when the rider was waiting at a red light, being a delivery rider and riding in the business park, and decreased while riding on a two-lane road, being middle-aged or older, in the residential district, and riding with an adult passenger. Traffic violations were more prevalent in the residential district than in the city center. There were also fewer violations in the afternoon and on a two-lane road. Since almost all observed riders wore a helmet (98.9\%), the regression model for unhelmeted riding was not computed.
Middle-aged and older riders were less likely to use the phone or partake in other secondary tasks while riding compared to young riders. The finding was consistent with the observational studies on German cyclists and car drivers (Huemer et al., 2019; Vollrath et al., 2016). Previous studies found younger drivers generally to be more prone to traffic errors and violations (Chang \& Yeh, 2007; Jensupakarn \& Kanitpong, 2018; Porter \& Berry, 2001; Yang \& Najm, 2007). For instance, in Vietnam, both car drivers and motorcyclists under 30 were more likely to neglect turn signals (Nguyen-Phuoc et al., 2019). Similarly, the likelihood of ignoring two-stage left turns was higher in younger Taiwanese motorcyclists (Pai et al., 2013). Chang and Yeh (2007) also found that Taiwanese motorcyclists between 20 to 29 were twice more likely to be involved in crashes than older riders.

For gender, secondary task engagement was higher in males than in females. When looking at phone use, the difference between the genders was not significant despite a higher percentage of phone use in males. The effect of gender on traffic violations was also examined: the frequency of carrying out any traffic violation was lower in female riders, but the difference did not reach a significance level. The influence of gender on distracted riding was inconsistent in past studies. In a roadside survey on the motorcycle and electric bike users in Vietnam, the odds of phone use were higher in males than females (Truong et al., 2016). 10.2\% of male riders made phone calls or operated the mobile phone, while only $5.4 \%$ of female riders did these. In the investigation in Malaysia, however, female motorcycle riders showed a higher frequency of phone use than males (Rusli et al., 2020). Similarly, the study on German cyclists discovered a higher prevalence of distraction in female riders (Huemer et al., 2019). No significant difference between female and male riders for traffic violations was discovered in the regression model, although the frequency of traffic violations was higher in males. Results in most studies showed that male drivers were more likely to break traffic rules, carry out risky driving behaviors, and be involved in accidents (González-Iglesias et al., 2012; OviedoTrespalacios \& Scott-Parker, 2018; Yagil, 1998). A local survey investigating motorcyclists in the Taipei metropolitan area also reflected the same trend: male riders reported a higher tendency of violating traffic regulations than their female counterparts (Chang \& Yeh, 2007).

Whether carrying passengers can help prevent risk-taking behaviors among motorcyclists is inconsistent across studies. Compared to riding alone, the Taiwanese motorcyclists in this study carrying another passenger were more likely to be distracted but less likely to use mobile phones. The finding was similar to the observation in Vietnam, whereas riding with passengers led to a reduced phone use rate (Truong et al., 2016). Nguyen-Phuoc et al. (2019) also found that the frequency of signal use at intersections was higher among riders carrying passengers than those riding alone in the observation in Vietnam. On the other hand, the presence of motorcycle passengers was associated with un-helmeted riding, red-light running, and phone use in a Malaysian study (Rusli et al., 2020). Likewise, the research on Taiwanese cyclists also discovered a decreased helmet use rate among cyclists carrying a passenger (Chi et al., 2019).

According to the present observation in Taiwan, phone use and traffic violations were both higher in delivery motorcyclists. The percentage of phone use among delivery and nondelivery riders was $18.2 \%$ and $4.1 \%$. The frequency of delivery workers breaking any traffic rule was $8.5 \%$, which was also higher than non-delivery riders (5.7\%). Professional drivers often work under time pressure and thus have a higher rate of traffic violations, which puts them at an increased accident risk. In Taiwan, the crash rate per 100,000 vehicles was 1651 for private passenger cars and 2439 for cargo truck 
drivers (MOTC, 2021). However, the crash data for delivery motorcycles are unfortunately unavailable in Taiwan; every motorcycle here requires a license plate upon registration, but unlike cars, the license does not specify if a motorcycle is for professional or private use. The probability of sustaining severe injuries in crashes was positively related to riders' traffic violation behavior (Chung et al., 2014). Therefore, the high prevalence of phone use and traffic violations among delivery motorcyclists in Taiwan was alarming.

Past research has shown that drivers were more likely to initiate phone use while waiting at a red light (Huth et al., 2015). A similar trend was found in Taiwanese motorcyclists at the three signalized intersections. The red light was the strongest predictor for phone use with an OR of $11.47 \mathrm{com}$ pared to the green light. Motorcyclists seem to anticipate a lower risk for secondary task engagement while standing in front of red lights compared to moving in traffic, suggesting that they interpret the waiting time as a pause from the riding task. Aside from traffic signals, temporal variables were also constantly evaluated in roadside surveys worldwide, while many of them differentiate the time into peak hours and nonpeak hours. The findings of Rusli et al. (2020) revealed that unhelmet riding and turn-signal neglect among motorcyclists were more common during non-peak hours; similarly, the two-stage turn violation was more prevalent in non-rush hours in the investigation in Taiwan (Pai et al., 2013). In the present study, motorcyclists riding in the afternoon were less likely to break traffic rules compared to riding at noon; yet the time of the day was not associated with distracted riding or phone use. Nevertheless, when considering the traffic flow during the observation session, the odds ratios of secondary task engagement and traffic violation were not significantly different between high and low traffic density.

To examine the effect of location on riders' behaviors, observations were done in three different areas. Phone use was higher in the city center than in the residential district, which might be caused by a long traffic light circle in the city. On the contrary, traffic violations were more prominent in the residential district. The increased rate of violation was possibly related to a lower perceived risk by motorcyclists since the traffic volume was much lower in the residential district than in the city center. In another local survey, motorcyclists in rural areas were also more likely to ignore the two-stage left turn (Pai et al., 2013). Road design was another major contextual variable: compared to one-lane roads, the prevalence of phone use and traffic violations was lower on two-lane roads in our study. One possible explanation is that the traffic flow was higher on two-lane roads, in addition to a higher speed limit. Both of them might increase motorcyclists' vigilance while riding on two-lane roads.

\subsection{Relationship between distracted riding, helmet non-use, and traffic violations}

Helmet non-use was positively associated with distracted riding and traffic violations among Taiwanese motorcyclists. $15.2 \%$ of helmet non-users were distracted, while the rate was only $7.2 \%$ for helmet users. The contrast was even stronger for traffic violations: $5.6 \%$ of helmeted riders carried out traffic violations in the observation, while $28.3 \%$ of un-helmeted riders violated rules. The finding in German cyclists was similar: un-helmeted riders were also more likely to show unsafe behaviors, such as partaking in any secondary task and not wearing light-colored clothing while riding (Huemer et al., 2019).

\subsection{Limitations and recommendations for future work}

The roadside observation is limited to examining "visible" distractions and behaviors among motorcyclists; other types of distraction (e.g., daydreaming) or risky behaviors (e.g., drunk driving) are harder to observe directly without further investigation. For future studies, one can conduct interviews or questionnaires based on psychological theories (like, e.g. Paris \& Van den Broucke, 2008) to supplement the field observation, which will provide insights into road users' motivation and intention for engaging in risk-taking behaviors. These methods can also help us understand why road users decide to take the risk and whether the decisionmaking is associated with latent traits (Huemer et al., 2018). Furthermore, the current study only differentiated phone use between handheld and on a phone mount, but not types of mobile phone operation. The types of usage are worth exploring in the future since previous research has found different adaptive driving behaviors when talking on the phone and screen operation (Onate-Vega et al., 2020; Oviedo-Trespalacios et al., 2017; Papantoniou et al., 2017; Phuksuksakul et al., 2021). Another shortcoming of the present study is the representativity of the data. All of the observations were done in dry weather conditions, while various studies have shown a decreased likelihood of distracted driving and phone use on rainy days among two-wheeler riders (Huemer et al., 2019; Rusli et al., 2020; Truong et al., 2016). It is also worth mentioning that all of the observations were carried out at 4-arm signalized junctions, while a past study in Taiwan revealed a higher probability of two-stage left turn violation at T- or Y-shaped intersections (Pai et al., 2013). Therefore, it is also recommended to carry out more observations to determine the influences of different weather conditions, locations, and types of road design on riders' risk-taking behaviors.

\section{CREDIT AUTHORSHIP CONTRIBUTION STATEMENT}

Wen Chieh Yang: Conceptualization, Investigation, Formal analysis, Visualization, Writing - Original Draft.

Anja Katharina Huemer: Conceptualization, Supervision, Methodology, Writing - Review \& Editing

\section{REFERENCES}

Chang, H.-L., \& Yeh, T.-H. (2007). Motorcyclist accident involvement by age, gender, and risky behaviors in Taipei, Taiwan. Transportation Research Part F: Traffic Psychology and Behaviour, 10(2), 109-122. https://doi.org/10.1016/i. trf.2006.08.001

Chang, L.-Y. (2005). Empirical Analysis of the Effectiveness of Mandated Motorcycle Helmet Use in Taiwan. Journal of the Eastern Asia Society for Transportation Studies, 6, 3629-3644. https://doi.org/10.11175/easts.6.3629

Chen, P.-L., Saleh, W., \& Pai, C.-W. (2017). Texting and walking: A controlled field study of crossing behaviours and inattentional blindness in Taiwan. Behaviour \& Information Technology, 36(4), 435-445. https://doi.org/10.1080/014492 9X.2016.1240234

Chi, C.-F., Chen, P.-L., Saleh, W., Tsai, S.-H., \& Pai, C.-W. (2019). Helmet non-use by users of bikeshare programs, electric bicycles, racing bicycles, and personal bicycles: An observational study in Taipei, Taiwan. International Journal of Sustainable Transportation, 13(2), 93-99. https://doi.org/10.10 80/15568318.2018.1441470

Chung, Y., Song, T.-J., \& Yoon, B.-J. (2014). Injury severity in delivery-motorcycle to vehicle crashes in the Seoul metropolitan area. Accident Analysis \& Prevention, 62, 79-86. https://doi.org/10.1016/j.aap.2013.08.024

de Waard, D., Westerhuis, F., \& Lewis-Evans, B. (2015). More screen operation than calling: The results of observing cyclists' behaviour while using mobile phones. Accident Analysis \& Prevention, 76, 42-48. https://doi.org/10.1016/j. aap.2015.01.004 
Dingus, T.A., Klauer, S.G., Neale, V.L., Petersen, A., Lee, S.E., Sudweeks, J.D., Perez, M.A., Hankey, J., Ramsey, D., Gupta, S., Bucher, C., Doerzaph, Z.R., Jermeland, J. \& Knipling, R.R. (2006). The 100-car naturalistic driving study, Phase II-results of the 100-car field experiment (No. HS-810 593).

Elliott, M. A., Baughan, C. J., \& Sexton, B. F. (2007). Errors and violations in relation to motorcyclists' crash risk. Accident Analysis \& Prevention, 39(3), 491-499. https://doi.org/10.1016/j.aap.2006.08.012

González-Iglesias, B., Gómez-Fraguela, J. A., \& Luengo-Martín, M. Á. (2012). Driving anger and traffic violations: Gender differences. Transportation Research Part F: Traffic Psychology and Behaviour, 15(4), 404-412. https://doi.org/10.1016/j.trf.2012.03.002

Huemer, A. K., Gercek, S., \& Vollrath, M. (2019). Secondary task engagement in German cyclists - An observational study. Safety Science, 120, 290-298. https://doi.org/10.1016/j. ssci.2019.07.016

Huemer, A. K., Schumacher, M., Mennecke, M., \& Vollrath, M. (2018). Systematic review of observational studies on secondary task engagement while driving. Accident Analysis \& Prevention, 119, 225-236. https://doi.org/10.1016/j. aap.2018.07.017

Huemer, A. K., \& Vollrath, M. (2012). Ablenkung durch fahrfremde Tätigkeiten-Machbarkeitsstudie. https://opus4.hbz-nrw.de/ opus45-bast/frontdoor/index/index/docId/350

Huth, V., Sanchez, Y., \& Brusque, C. (2015). Drivers' phone use at red traffic lights: A roadside observation study comparing calls and visual-manual interactions. Accident Analysis \& Prevention, 74, 42-48. https://doi.org/10.1016/j. aap.2014.10.008

Jensupakarn, A., \& Kanitpong, K. (2018). Influences of motorcycle rider and driver characteristics and road environment on red light running behavior at signalized intersections. Accident Analysis \& Prevention, 113, 317-324. https://doi.org/10.1016/j. aap.2018.02.007

Lam, C., Wiratama, B. S., Chang, W.-H., Chen, P.-L., Chiu, W.-T., Saleh, W., \& Pai, C.-W. (2020). Effect of motorcycle helmet types on head injuries: Evidence from eight level-I trauma centres in Taiwan. BMC Public Health, 20(1), 78. https://doi.org/10.1186/ s12889-020-8191-1

Li, Q., Adetunji, O., Pham, C. V., Tran, N. T., Chan, E., \& Bachani, A. M. (2020). Helmet use among motorcycle riders in Ho Chi Minh City, Vietnam: Results of a five-year repeated cross-sectional study. Accident Analysis \& Prevention, 144, 105642. https://doi.org/10.1016/j.aap.2020.105642

Libby, D., \& Chaparro, A. (2009). Text Messaging versus Talking on a Cell Phone: A Comparison of their Effects on Driving Performance. Proceedings of the Human Factors and Ergonomics Society Annual Meeting, 53(18), 1353-1357. https://doi.org/10.1177/154193120905301840

Ministry of Transportation and Communications. (2021a). Commonly Used Transportation Statistics. https://stat.motc. gov.tw/mocdb/stmain.jsp?sys=100\&funid=defjsp

Ministry of Transportation and Communications. (2021b). International Transportation Statistics. https://www.motc.gov. tw/en/home.jsp?id=2204\&parentpath $=0 \% 2 \mathrm{C} 154 \&$ mcustomize $=$ statistics401.jsp

Ministry of Transportation and Communications. (2021c). Motor Vehicle Registration. https://stat.motc.gov.tw/mocdb/stmain. isp?sys $=100 \&$ funid $=e 3301$

National Highway Traffic Safety Administration. (2021). Traffic Safety Facts. https://crashstats.nhtsa.dot.gov/Api/Public/ ViewPublication/813112

National Police Agency. (2021). Fatality Traffic Accidents: Causes. https://ba.npa.gov.tw/npa/stmain.jsp?sys $=210 \&$ funid $=q 06010$ 501\&type $=1$

Nguyen-Phuoc, D. Q., Tran, A. T. P., De Gruyter, C., Kim, I., $\&$ Su, D. N. (2019). Turn signal use among car drivers and motorcyclists at intersections: A case study of Da Nang,
Vietnam. Accident Analysis \& Prevention, 128, 25-31. https://doi.org/10.1016/i.aap.2019.03.012

Observation 3.0: Feldbeobachtung mit dem Tablet. (2018). Ingenieur- und Verkehrspsychologie, TU Braunschweig. https://www.tu-braunschweig.de/psychologie/ verkehrspsychologie/software

Onate-Vega, D., Oviedo-Trespalacios, O., \& King, M. J. (2020). How drivers adapt their behaviour to changes in task complexity: The role of secondary task demands and road environment factors. Transportation Research Part F: Traffic Psychology and Behaviour, 71, 145-156. https://doi.org/10.1016/j. trf.2020.03.015

Oviedo-Trespalacios, O., \& Scott-Parker, B. (2018). The sex disparity in risky driving: A survey of Colombian young drivers. Traffic Injury Prevention, 19(1), 9-17. https://doi.org/10.1080/1 5389588.2017.1333606

Pai, C.-W., Hsu, J.-J., Chang, J.-L., \& Kuo, M.-S. (2013). Motorcyclists violating hook-turn area at intersections in Taiwan: An observational study. Accident Analysis \& Prevention, 59, 1-8. https://doi.org/10.1016/j. aap. 2013.04.034

Pai, C.-W., Lin, H.-Y., Tsai, S.-H., \& Chen, P.-L. (2018). Comparison of traffic-injury related hospitalisation between bicyclists and motorcyclists in Taiwan. PLOS ONE, 13(1), e0191221. https://doi.org/10.1371/journal.pone.0191221

Paris, H., \& Van den Broucke, S. (2008). Measuring cognitive determinants of speeding: An application of the theory of planned behaviour. Transportation Research Part F: Traffic Psychology and Behaviour, 11(3), 168-180.

Papantoniou, P., Papadimitriou, E., \& Yannis, G. (2017). Review of driving performance parameters critical for distracted driving research. Transportation Research Procedia, 25, 1796-1805. https://doi.org/10.1016/j.trpro.2017.05.148

Pérez-Núñez, R., Hidalgo-Solórzano, E., Vera-López, J. D., Lunnen, J. C., Chandran, A., Híjar, M., \& Hyder, A. A. (2014). The Prevalence of Mobile Phone Use Among Motorcyclists in Three Mexican Cities. Traffic Injury Prevention, 15(2), 148-150. https://doi.org/10.1080/15389588.2013.802776

Phuksuksakul, N., Kanitpong, K., \& Chantranuwathana, S. (2021). Factors affecting behavior of mobile phone use while driving and effect of mobile phone use on driving performance. Accident Analysis \& Prevention, 151, 105945. https://doi. org/10.1016/j.aap.2020.105945

Porter, B. E., \& Berry, T. D. (2001). A nationwide survey of self-reported red light running: Measuring prevalence, predictors, and perceived consequences. Accident Analysis \& Prevention, 33(6), 735-741. https://doi.org/10.1016/S00014575(00)00087-7

R Core Team (2021). R: A language and environment for statistical computing. R Foundation for Statistical Computing. https://www.R-project.org/.

Rusli, R., Oviedo-Trespalacios, O., \& Abd Salam, S. A. (2020). Risky riding behaviours among motorcyclists in Malaysia: A roadside survey. Transportation Research Part F: Traffic Psychology and Behaviour, 74, 446-457. https://doi.org/10.1016/i. trf.2020.08.031

Thapa, R., Codjoe, J., Ishak, S., \& McCarter, K. S. (2015). Post and During Event Effect of Cell Phone Talking and Texting on Driving Performance-A Driving Simulator Study. Traffic Injury Prevention, 16(5), 461-467. https://doi.org/10.1080/15389588. 2014.969803

Truong, L. T., \& Nguyen, H. T. T. (2019). Mobile phone related crashes among motorcycle taxi drivers. Accident Analysis \& Prevention, 132, 105288. https://doi.org/10.1016/j. aap.2019.105288

Truong, L. T., Nguyen, H. T. T., \& De Gruyter, C. (2016). Mobile phone use among motorcyclists and electric bike riders: A case study of Hanoi, Vietnam. Accident Analysis \& Prevention, 91, 208-215. https://doi.org/10.1016/j.aap.2016.03.007 
Truong, L. T., Nguyen, H. T. T., \& Gruyter, C. D. (2019). Mobile phone use while riding a motorcycle and crashes among university students. Traffic Injury Prevention, 20(2), 204-210. https://doi.org/10.1080/15389588.2018.1546048

Victor, T., Bärgman, J., Boda, C.-N., Dozza, M., Engström, J., Flannagan, C., Lee, J.D. \& Markkula, G. (2014). Analysis of Naturalistic Driving Study Data: Safer Glances, Driver Inattention, and Crash Risk. Trans-portation Research Board of the National Academics. Online: http://online- pubs.trb.org/ onlinepubs/shrp2/SHRP2prepubS08ARe- port.pdf

Vollrath, M., Huemer, A. K., Teller, C., Likhacheva, A., \& Fricke, J. (2016). Do German drivers use their smartphones safely?-Not really! Accident Analysis \& Prevention, 96, 29-38. https://doi. org/10.1016/i.aap.2016.06.003

Wiratama, B. S., Chen, P.-L., Ma, S.-T., Chen, Y.-H., Saleh, W., Lin, H.-A., \& Pai, C.-W. (2020). Evaluating the combined effect of alcohol-involved and un-helmeted riding on motorcyclist fatalities in Taiwan. Accident Analysis \& Prevention, 143, 105594. https://doi.org/10.1016/j.aap.2020.105594

Woo, T. H., \& Lin, J. (2001). Influence of mobile phone use while driving: The experience in Taiwan. IATSS Research, 25(2), 15-19. https://doi.org/10.1016/S0386-1112(14)60066-2

Yagil, D. (1998). Gender and age-related differences in attitudes toward traffic laws and traffic violations. Transportation Research Part F: Traffic Psychology and Behaviour, 1(2), 123-135. https://doi.org/10.1016/S1369-8478(98)00010-2

Yang, C. Y. D., \& Najm, W. G. (2007). Examining driver behavior using data gathered from red light photo enforcement cameras. Journal of Safety Research, 38(3), 311-321. https://doi. org/10.1016/j.jsr.2007.01.008

Young, R. (2017). Removing Biases from Crash Odds Ratio Estimates of Secondary Tasks: A New Analysis of the SHRP 2 Naturalistic Driving Study Data (No. 2017-01-1380). SAE Technical Paper. 